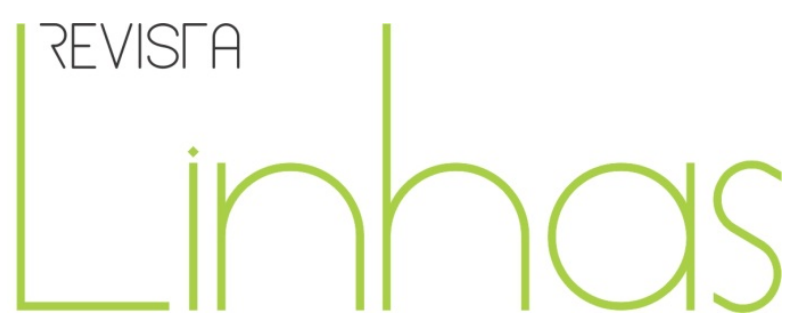

\title{
O livro didático de História como objeto material da cultura escolar: uma experiência a partir da Rede Salesiana de Escolas
}

\begin{abstract}
Resumo
$\mathrm{Na}$ busca por novas perspectivas envolvendo o material didático de História, este artigo apresenta parte do resultado da pesquisa de mestrado, o qual aborda a relação entre o livro didático de História do ensino médio e a sua organização curricular com a produção de uma cultura escolar específica da Rede Salesiana de Escolas (RSE). Em sua proposta pedagógica, a RSE compreende o livro didático como o principal produto da cultura escolar. Nesse sentido, procurase direcionar a discussão concebendo a formação da RSE e suas normativas como integrantes do processo de formação e espaço de apropriação de conhecimentos e valores. Compreende-se o processo educacional sob o prisma da cultura sob a acepção de Julia (2001) e Forquin (1993). Aborda-se o livro didático e o currículo como produtos da cultura escolar considerando que as escolas são portadoras de individualidades e de culturas particulares, no entanto estão submetidas à padronização do ensino e da aprendizagem por meio da utilização do material didático como intercessor para a constituição de uma cultura escolar uniforme.
\end{abstract}

Palavras-chave: História; Estudo e ensino; Livros didáticos; Currículos; Rede Salesiana de Escolas.

\author{
Geane Kantovitz \\ Mestre em Educação pela \\ Universidade Federal de Santa \\ Catarina - UFSC - Brasil \\ geaneks@hotmail.com
}

\footnotetext{
Para citar este artigo:

KANTOVITZ, Geane. O livro didático de História como objeto material da cultura escolar: uma experiência a partir da Rede Salesiana de Escolas. Revista Linhas. Florianópolis, v. 16, n. 30, p. 152 - 179, jan./abr. 2015.
}

DOI: $10.5965 / 1984723816302015152$

http://dx.doi.org/10.5965/1984723816302015152

\footnotetext{
*Esta pesquisa contou com financiamento do CNPq, na modalidade bolsa de estudo.
} 


\title{
The history course book as a material object of the school culture: an experience from the Salesian Schools Network
}

\begin{abstract}
Searching for new perspectives involving the history course book, this article presents part of the result of the master research which addresses the relation between the high school teaching history course book and its curricular organization with the production of one specific school culture from the Salesian Schools Network (RSE in portuguese). In its pedagogical proposal, the RSE includes the course book as the main product of the school culture. In this sense, it seeks to direct the discussion conceiving the formation of the Salesian Schools Network and its policies as members of the process of formation and space appropriation of knowledge and values. It understands the educational process through the prism of culture under the conception of Julia (2001) and Forquin (1993). It addresses the course book and curriculum as products of the school culture considering that schools are suffering from individual and particular cultures, however they are undergoing teaching and learning standardization through the use of course books as an intercessor for the constitution of a standardized school culture.
\end{abstract}

Keywords: History ; Study and teaching; Course book; Curriculum; Salesian Schools Network. 
Compreender as práticas escolares sob o prisma da cultura escolar é considerar aspectos que fazem parte do cotidiano da escola, entre eles os objetos materiais, os espaços e tempos escolares, as disciplinas curriculares e a ação dos sujeitos. Nesse sentido, a cultura escolar materializa-se como a "caixa preta", expressão utilizada por alguns pesquisadores, entre eles Vidal (2010), que possibilita "entrar" no cotidiano da escola para analisar tanto as práticas escolares, na acepção de Julia (2001), quanto na reorganização e reestruturação dos saberes, na visão de Forquin (1993). Compreendida como uma categoria que migra de uma visão homogênea/ideológica e reprodutivista da escola para uma visão matizada pelas rupturas e mudanças, a cultura escolar é a categoria de análise que norteia a discussão desse artigo sobre o livro didático como objeto material da cultura escolar.

Corroborando com o movimento de "rompimento" com a historiografia tradicional ${ }^{1}$, a cultura escolar faz emergir novas fontes teóricas e metodológicas que oportunizam aos pesquisadores novos questionamentos sobre a História da Educação, contribuindo, portanto, para um entendimento das instituições escolares como produtoras e reprodutoras de culturas e saberes.

De acordo com Viñao Frago e Escolano (1998, p. 14), um olhar diferenciado foi lançado sobre os objetos de pesquisa, como "autobiografias e diários, os relatórios de visitas de inspeção, as descrições do edifício, das salas de aula, ou da vida escolar em geral, as memórias de arquitetos, fotografias e plantas, cadernos e diários de classe, exames, mobiliários".

Para compreender a escola como espaço de apropriação de conhecimento e valores, faz-se necessário o entendimento de alguns conceitos de cultura escolar que direcionam a presente análise. Julia (2001, p. 10) define cultura escolar como:

\footnotetext{
${ }^{1}$ De acordo com Burke, a historiografia tradicional pode ser resumida em seis pontos: (1) A História diz respeito essencialmente à política. (2) A História como uma narrativa de acontecimentos. (3) Oferece uma visão de cima, centrada em grandes homens, estadistas, generais ou ocasionalmente eclesiásticos. (4) Uma História baseada em documentos. (5) Falha na avaliação da variedade de questionamentos dos historiadores. (6) A História é objetiva (BURKE, 1992, p. 10-15).
} 
um conjunto de normas que definem conhecimentos a ensinar e conduta a inculcar, e um conjunto de práticas que permitem a transmissão desses conhecimentos e a incorporação desses comportamentos; normas e práticas coordenadas a finalidades que podem variar segundo épocas (finalidades religiosas, sociopolíticas ou simplesmente de socialização).

Para Julia (2001, p. 10-11), estudar a cultura escolar é estudar os processos de práticas escolares, ou seja, práticas que possibilitam a transmissão de conhecimentos e a imposição de valores e condutas destinados à escola. Ainda, de acordo com o autor, para analisar a cultura escolar, é necessário analisar o conjunto de normas e práticas definidoras dos conhecimentos que determinado grupo social deseja que fosse ensinado, e os valores e comportamentos a serem seguidos.

O autor aborda a cultura escolar numa concepção de rupturas, que emerge pensar nas instituições escolares como profícuos espaços de mudanças em tempos e espaços distintos. Julia (2001) considera as práticas e conteúdos como um movimento que a cada espaço e em cada período histórico atende a especificidades próprias de instituições com interações sociais próprias e culturas diversificadas. A cultura escolar, para ele, evidencia que a escola não é somente um lugar de transmissão de conhecimentos, mas é, ao mesmo tempo, um lugar de "inculcação de comportamentos e de habitus." (JULIA, 2001, p. 14).

A proposta de Julia ao formular o conceito era atribuir uma ênfase às práticas escolares e não somente às normas. Crítico à ideia de Bourdieu (1982) da escola reprodutivista, ele via o espaço escolar como um lugar de produção cultural e não de reprodução. Julia (2001) convida os historiadores da educação a se interrogarem sobre as práticas cotidianas, sobre o funcionamento interno da escola.

Considerando as especificidades da reorganização e reestruturação dos saberes construídos na escola, a categoria de cultura escolar na compreensão de Forquin (1993) também auxilia na compreensão do seu conceito. O autor define cultura escolar como: “o conjunto de conteúdos cognitivos e simbólicos que selecionados, organizados, 'normatizados', sob o efeito de imperativos de didatização, constituem habitualmente o objeto de uma transmissão deliberada no contexto das escolas." (FORQUIN, 1993, p. 167). 
Com base no conceito de Forquin, pode-se inferir que a cultura escolar, muito mais que na sua amplitude, é inserida no contexto escolar por intermédio de práticas cotidianas e dos conteúdos transmitidos em sala de aula previamente organizados.

Em relação à cultura da escola, o autor destaca que, "a escola é também 'mundo social', que tem suas características de vida próprias, seus ritmos e seus ritos, seu imaginário, seus modos próprios de regulação e de transgressão, seu regime próprio de produção e de gestão de símbolos." (FORQUIN, 1993, p. 167).

Dessa maneira, tratando-se da necessidade de perceber as instituições escolares como mundo social, portadoras de individualidades e de culturas particulares, Forquin considera a dimensão cultural como um dos estruturantes da educação escolar e um mecanismo para a compreensão das relações que acontecem no cotidiano escolar, quer dizer, como se expressam as diferentes dimensões culturais no dia a dia das escolas.

No cotejo dos conceitos emergidos por Julia (2001) e Forquin (1993), ambos os autores rompem com a noção de permanência e resistência às mudanças. No entanto, alguns distanciamentos são percebidos, principalmente por Forquin (1993) defender a escola como um espaço de transposição didática. Porém, essa transposição didática não pode ser pensada nos moldes tradicionais, mas sim num movimento de transformação do conhecimento produzido pela academia, ou seja, o autor não apenas recorta e reproduz o conhecimento e materiais culturais, mas efetua a reorganização e reestruturação desses saberes perante a necessidade da transposição didática.

Enfim, considerando suas aproximações e distanciamentos, os autores repousam na capacidade de oferecer indícios para o entendimento da ação dos homens no seu espaço e tempo histórico. O desafio é explorar os limites operatórios da categoria de análise, questionar o seu potencial explicativo e identificar as lacunas que deixa nas interpretações. Nesse sentido a cultura escolar advoga tanto numa dimensão sincrônica quanto diacrônica ao conferir atenção à ação dos indivíduos e nas relações que se estabelecem com os objetos culturais do interior da escola.

Desse modo, concebendo a Rede Salesiana de Escolas (RSE) como uma instituição escolar e suas normativas como integrante do processo da formação de uma prática 
pedagógica específica e singular por meio do livro didático, entende-se que é oportuna uma análise com as lentes da cultura escolar como categoria teórica e metodológica de investigação.

O estudo das instituições escolares está inserido numa análise contundente dos espaços sociais destinados ao processo de ensino e aprendizagem, vale dizer, por meio da compreensão da vivência escolar, de suas normas e valores inculcados é possível compreender a cultura escolar em vigor em determinados espaços e instituições escolares.

Segundo Gatti Júnior e Oliveira (2002, p. 20),

a história das instituições educacionais almeja dar conta dos vários atores envolvidos no processo educativo, investigando aquilo que passa no interior das escolas, gerando um conhecimento mais aprofundando destes espaços sociais destinados aos processos de ensino e de aprendizagem, por meio da busca da apreensão daqueles elementos que conferem identidade à instituição educacional, ou seja, daquilo que the confere um sentido único no cenário social do qual fez ou ainda faz parte, mesmo que ela se tenha transformado no decorrer dos tempos.

Assim, levando-se em conta que "a cultura escolar é efetivamente uma cultura conforme, e seria necessário definir, a cada período, os limites que traçam a fronteira do possível e do impossível” (JULIA, 2001, p. 32), as escolas da RSE do Brasil empenham-se em elaborar uma proposta educativa unificada para que todas as instituições do país ligadas à Congregação possam ser normatizadas e inseridas numa cultura escolar padronizada conforme os princípios pedagógicos da instituição.

\section{A Rede Salesiana de escolas e sua proposta pedagógica}

De acordo com Bisewski (2008), a RSE, no Brasil, nasceu a partir de um processo feito pelas Escolas Salesianas na América (ESA), em que foram iniciadas e analisadas as ideias do trabalho em rede, a partir de 1994. O primeiro encontro entre as escolas 
salesianas da América foi realizado em 1994, na cidade de Cumbayá (Cumbaya I), Equador. Em 2001, no mesmo país, foi realizado o segundo encontro entre as Escolas Salesianas na América (Cumbaya II). É a partir do segundo encontro que os Salesianos de Dom Bosco e as Filhas de Maria Auxiliadora, aqui no Brasil, iniciaram o processo de uma ação integrada como Rede Educativa e, a partir de 2002, os superiores responsáveis pelos Salesianos de Dom Bosco (SDB), por meio da Conferência das Inspetorias dos Salesianos de Dom Bosco do Brasil (CISBRASIL), e pelas Filhas de Maria Auxiliadora (FMA), por intermédio da Conferência Interinspetorial do Brasil (CIB), nomearam uma Direção da RSE, ou seja, surgiu oficialmente a Rede Salesiana de Escolas.

Com a integração das escolas salesianas à Rede, surgem os direcionamentos para uma proposta educativa baseada nos princípios de Dom Bosco, estabelecendo como princípio norteador, para garantir a unidade e os interesses pedagógicos e religiosos da Congregação, o Marco Referencial do Projeto Pedagógico da RSE, finalizado e implantado no Brasil em 2005 (Quadro 1). Assim, organiza-se o Marco Referencial do Projeto Pedagógico:

\begin{tabular}{|l|l|}
\hline \multicolumn{2}{|c|}{ Projeto Pedagógico - Marco Referencial } \\
\hline Apresentação & \\
\hline Introdução & a- Perfil do educando \\
\hline Marco situacional - a Escola Salesiana & b- Crenças e valores \\
Marco doutrinal - Projeto de & c- Educação integral \\
pessoa e de sociedade & d- Formação em valores e atitudes \\
& a- Princípios gerais \\
& b- Princípios orientadores do processo de \\
& c- Cnsino - aprendizagem \\
& d- Organização dos conteúdos \\
& e- Tempos e espaços \\
\hline A RSE a serviço da educação & a- Formação dos educadores \\
& b- Formação dos educadores \\
& c- Apoio aos pais \\
\hline Avaliação permanente & \\
\hline Bibliografia & \\
\hline
\end{tabular}

Quadro 1: Organização do Marco Referencial do Projeto Pedagógico da RSE. Fonte: REDE, 2005, p. 3. 
Em suas trinta páginas, o que predomina na Proposta Pedagógica são as diretrizes gerais da educação salesiana e de como deve ser conduzido o processo de concretização da proposta educativa em todas as escolas associadas à Rede. Percebe-se no documento a preocupação com a uniformização do âmbito escolar na parte destinada à concepção curricular:

O professor deve atuar com base num projeto coerente e coletivamente elaborado, evitando-se, assim, que estilos individuais acabem por determinar o funcionamento das escolas, especialmente quando experiências de trabalho integrado e cooperativo inexistem na realidade que se deseja modificar. (REDE, 2005, p. 18)

Considerando a contribuição de Julia (2001) ao inferir sobre a importância de aglutinar as análises macro com as análises micro da instituição escolar, foi inferida uma pesquisa nas escolas salesianas de Santa Catarina com o objetivo de compreender a densidade em que a Proposta Pedagógica da Rede é apreendida pelas escolas.

Desse modo, realizou-se uma pesquisa tanto da organização interna das escolas, quanto do material didático de História como mecanismo que movimenta para a formação de uma cultura escolar nos moldes salesianos.

As instituições de ensino integrantes dessa Rede no Estado catarinense são: o Colégio Dom Bosco e o Instituto Maria Auxiliadora, em Rio do Sul; o Colégio São Paulo, em Ascurra; o colégio Salesiano Itajaí, em Itajaí; e o Colégio Auxiliadora, em Campos Novos.

Apesar de a proposta pedagógica da Rede estabelecer as diretrizes gerais de funcionamento e direcionamentos normativos, o que se observa nas cinco escolas de Santa Catarina são as adaptações individuais de cada uma delas. Embora façam parte da Rede e sigam o Marco Referencial, as escolas se adaptam de acordo com suas especificidades. Um exemplo disso é a organização bimestral ou trimestral de cada instituição. Das escolas salesianas de Santa Catarina, uma delas estrutura-se bimestralmente, as demais utilizam o trimestre conforme orientação geral da Proposta Pedagógica. Também se verifica uma autonomia na organização da grade curricular, em 
especial da disciplina de História. Nas cinco escolas, o número de aulas semanais de História varia de uma a três aulas em cada série, embora a proposta da Rede e do livro didático seja de, no mínimo, duas aulas semanais:

\begin{tabular}{|l|l|l|l|}
\hline Escola Salesiana & $\begin{array}{l}\text { Quantidade de de } \\
\text { aulas na } 1^{\mathrm{a}} \text { série }\end{array}$ & $\begin{array}{l}\text { Quantidade } \\
\text { aulas na } 2^{\mathrm{a}} \text { série }\end{array}$ & $\begin{array}{l}\text { Quantidade de } \\
\text { aulas na } 3^{\mathrm{a}} \text { série }\end{array}$ \\
\hline Colégio Dom Bosco & 2 aulas & 2 aulas & 1 aula \\
\hline $\begin{array}{l}\text { Instituto Maria } \\
\text { Auxiliadora }\end{array}$ & 2 aulas & 2 aulas & 2 aulas \\
\hline $\begin{array}{l}\text { Colégio Salesiano } \\
\text { Itajaí }\end{array}$ & 2 aulas & 2 aulas & 3 aulas \\
\hline Colégio Auxiliadora & 2 aulas & 2 aulas & 2 aulas \\
\hline Colégio São Paulo & 2 aulas & 2 aulas & 2 aulas \\
\hline
\end{tabular}

Quadro 2: Distribuição das aulas de História no ensino médio das escolas envolvidas na pesquisa. Fonte: Levantamento de dados realizado nas escolas salesianas de SC pela pesquisadora.

Desse modo, percebe-se que a diversidade pode ser estabelecida no interior das instituições, desde que as diretrizes gerais sejam seguidas e obedecidas de acordo com o Marco Referencial da RSE, ou seja, a diversidade pode ser tolerada no interior da instituição, contanto que as diretrizes gerais sejam aceitas e seguidas.

De acordo com Julia (2001), "não existe na história da educação estudo mais tradicional que o das normas que regem as escolas ou os colégios, pois nós atingimos mais facilmente os textos reguladores e os projetos pedagógicos que as próprias realidades." (JULIA, 2001, p. 19). Ainda para o autor, é importante destacar dois pontos em relação à análise das normas e das finalidades que regem a escola. Um dos pontos centrais é que "os textos normativos devem sempre nos reenviar às práticas" (JULIA, 2001, p. 19). Nesse sentido, pode-se inferir uma relação entre as normas impostas pela Proposta Pedagógica da RSE (que pode ser considerado nessa perspectiva como um texto normativo) e as práticas escolares em seu cotidiano. Conforme Julia (2001, p. 10),

Normas e práticas não podem ser analisadas sem se levar em conta o corpo profissional dos agentes que são chamados a obedecer a essas ordens e, portanto, a utilizar dispositivos pedagógicos encarregados de 
facilitar sua aplicação, a saber, os professores primários e os demais professores.

O segundo ponto destacado por Julia (2001, p. 19) no que se refere à análise das normas e das finalidades que regem a escola, é de que "mais que nos tempos de calmaria, é nos tempos de crise e de conflitos que podemos captar melhor o funcionamento real das finalidades atribuídas à escola". O autor ainda prossegue destacando que "temos sempre a tendência, ao lermos textos normativos ou projetos pedagógicos, de destacar a tentação 'totalitária', ou ao menos englobante de todo o ser da criança, que os caracteriza". (JULIA, 2001, p. 19). Além disso, acrescenta que "no momento em que uma nova diretriz redefine as finalidades atribuídas ao esforço coletivo, os antigos valores não são, no entanto, eliminados como por milagre, as antigas divisões não são apagadas, novas restrições somam-se simplesmente às antigas" (JULIA, 2001, p. 23).

A Proposta Pedagógica da RSE, ao ser pensada e elaborada, também passou por resistências ${ }^{2}$ e por um constante processo de adaptação e readaptação das escolas da Rede. A RSE, ao propor novas diretrizes para a educação nas escolas salesianas do Brasil, manteve muitas das tradições cristãs que fundamentam a filosofia da Congregação, inclusive os princípios do Sistema Salesiano de Educação. Porém, novas perspectivas e adequações deram-se no cotidiano escolar, incluindo a produção e implantação de livro didático próprio para todas as escolas salesianas do país.

Os livros didáticos são considerados, pela Rede, importante componente para a efetivação da Proposta Pedagógica no Brasil. O fragmento, a seguir, explicita a importância dessa proposta:

O material didático da RSE assume em todos os sentidos um papel fundamental nesse Projeto, por se tratar de um dos instrumentos principais para sua implantação, além de suscitar a formação continuada dos professores e de garantir apropriação dos conhecimentos pelo

\footnotetext{
${ }^{2}$ Refere-se aqui às resistências por parte dos professores e dos alunos, fato este que pôde ser diagnosticado na pesquisa.
} 
aluno. A preocupação com os princípios aqui explicitados perpassa tudo o que é produzido para o professor e o aluno, de tal forma que o material didático torna visível, concretiza e confere unidade a este Marco Referencial. (REDE, 2005, p. 18)

Nessa linha de pensamento, a produção de livro didático está diretamente inserida no processo de ensino e aprendizagem do cotidiano escolar. Em relação à disciplina de História, o livro didático passa a ser o norteador do currículo escolar, isto é, ele direciona os conhecimentos a serem ensinados em sala de aula. Portanto, o uso do livro didático pode ser considerado um importante aliado na prática pedagógica ou, contraditoriamente, um reprodutor de conteúdos e transmissor de conhecimentos predeterminados e concebidos por determinados grupos da sociedade.

Relativamente a essa discussão, Bittencourt destaca que

o livro didático independentemente da condição do professor, no transcorrer do século XIX, transformou-se em uma ferramenta de trabalho indispensável na sala de aula. Nos anos seguintes, 0 aperfeiçoamento técnico na fabricação do livro e a possibilidade de ser consumido por um número cada vez maior de alunos aliados à continuidade de uma precária formação do corpo docente fizeram do livro didático um dos símbolos da cultura escolar, um depositário privilegiado do saber a ser ensinado. (BITENCOURT, 2008a, p. 190)

Considerando o ensino de História e a produção de livro didático da RSE, primeiramente é necessário compreender o processo pelo qual a proposta pedagógica salesiana foi pensada e inserida nas escolas da Rede. Assim, em 2003 foi formada uma equipe pedagógica composta pela Conferência das Inspetorias das Filhas de Maria Auxiliadora do Brasil (CIB) e pela Conferência das Inspetorias dos Salesianos de Dom Bosco do Brasil (CISBRASIL), sob a orientação do grupo Mathema ${ }^{3}$, de São Paulo. O grupo Mathema, coordenado pelas professoras doutoras Kátia Cristina Stocco Smole e Maria

\footnotetext{
3 "O propósito do grupo MATHEMA é pesquisar e experienciar novos métodos de ensino e aprendizagem, assessorando e acompanhando escolas, órgãos públicos e organizações não governamentais voltadas para a educação, formando professores, provendo publicações, materiais e recursos pedagógicos que contribuam para o processo educativo e a melhoria do ensino público e privado." Fonte: http//www.mathema.com.br/>. Acesso em: 21 abr. de 2010.
} 
Ignez de Souza Vieira Diniz (também coordenadoras da equipe pedagógica da RSE), é responsável pela elaboração do livro didático, assessoria pedagógica e acompanhamento da divulgação dos livros a todas as escolas vinculadas ao Projeto Pedagógico da Rede. A professora Kátia Cristina Stocco Smole define a integração entre o grupo Mathema e a Rede Salesiana da seguinte forma:

O grupo Mathema foi chamado em 2001 para assessorar o projeto da Rede na elaboração das diretrizes pedagógicas, na seleção e coordenação dos trabalhos dos autores, na organização da linha mestra dos livros didáticos, sua elaboração, articulação e também, para a implantação do projeto pedagógico nas escolas. Coube a equipe também elaborar as primeiras ações de formação continuada para educadores da Rede. $^{4}$

Nessa trajetória, em 2005, as escolas da RSE recebem os primeiros livros didáticos e, gradativamente, passam a ser implantados em todas as escolas do Brasil.

Segundo a equipe pedagógica da RSE, os autores do livro didático foram selecionados pela equipe do grupo Mathema, os quais são profissionais das áreas específicas e são escolhidos de acordo com a sua especialização e suas afinidades com os princípios pedagógicos e educacionais do Sistema Preventivo Salesiano. O desafio proposto aos autores dos livros didáticos é que façam um trabalho em parceria com os docentes das escolas da Rede. Assim, desde 2005, com o início da implantação dos livros didáticos, os professores, coordenadores pedagógicos e autores dos livros reúnem-se anualmente em seus polos ${ }^{5}$ para discutirem o andamento e as possibilidades de melhoria e de revisão do material.

Quanto à elaboração e à seleção de conteúdos, o livro didático utilizado no ensino fundamental e médio foi programado para durar quatro anos (2004- 2007), sendo implantado gradativamente e sob a supervisão direta das equipes pedagógica e editorial,

\footnotetext{
4 Mensagem recebida de Kátia Cristina Stocco Smole via mensagem eletrônica no email geaneks@hotmail.com em 25/jul./2010.

${ }^{5}$ As escolas da RSE são divididas em polos; sendo, no total, seis: Manaus, Recife, Campo Grande, Belo Horizonte, São Paulo e Porto Alegre. As cinco escolas pesquisadas nesta dissertação fazem parte do polo de Porto Alegre; no total, o polo atende a onze escolas distribuídas no estado do Paraná e Porto Alegre.
} 
além de ser avaliado por um grupo de professores de diferentes universidades do Brasil. Além desse grupo, os professores e alunos avaliam anualmente os livros didáticos por meio de formulário próprio enviado para as escolas salesianas. Os livros da Rede não passam pela avaliação do Plano Nacional do Livro Didático (PNLD) ${ }^{6}$. Segundo entrevista cedida pela equipe pedagógica da Rede, os livros não passam pela avaliação do PNLD por serem livros não reutilizáveis, pois as atividades pedagógicas são elaboradas e devem ser realizadas no próprio livro, além de ser um material exclusivo para alunos e professores das escolas salesianas do país.

Delimitadas as diretrizes para a elaboração, produção e utilização dos livros didáticos, a coleção de História do ensino médio está sendo utilizada por alunos e professores, desde o ano de 2005, em todas as escolas salesianas do Brasil.

\section{Currículo e livro didático de História do ensino médio da RSE: produtores de uma cultura escolar salesiana}

Compreendido como o instrumento metodológico mais utilizado nas escolas salesianas, o livro didático de História é entendido como um conjunto de saberes que oficialmente deve ser transmitido aos alunos pela mediação do professor. Assim, auxiliando no processo de ensino e aprendizagem e na formação do pensamento histórico do aluno.

Para Bittencourt (2006, p. 72),

o livro didático é também um depositário de conteúdos escolares, suporte básico e sistematizador privilegiado dos conteúdos elencados pelas propostas curriculares; é por seu intermédio que são passados os conhecimentos e técnicas considerados fundamentais de uma

\footnotetext{
${ }^{6}$ O Programa Nacional do Livro Didático (PNLD) é o mais antigo dos programas voltados à distribuição de obras didáticas aos estudantes da rede pública de ensino brasileira e iniciou-se, com outra denominação, em 1929. Ao longo desses quase setenta anos, o programa se aperfeiçoou e teve diferentes nomes e formas de execução. O PNLD é voltado para a educação básica pública, incluindo as classes de alfabetização infantil.

Fonte: http://portal.mec.gov.br/index.php?option=com_content\&view=article\&id=12391\&ltemid=668. Acesso em: 11 de jan. de 2011.
} 
determinada época. O livro didático realiza uma transposição do saber acadêmico para o saber escolar no processo de explicitação curricular.

Portanto, o livro didático é entendido na sua complexidade. É percebido como “parte da história cultural da nossa civilização e como objeto que deve ser usado numa situação de ensino e aprendizagem e, nessa relação, há vários sujeitos: os autores, editor, trabalhadores, e, sobretudo professores e alunos" (OLIVEIRA, 2009, p. 81).

A compreensão do livro didático vai além do escrito entre as linhas da cultura material escolar, mas sim, entende-o como um recurso metodológico que traz questionamentos e problemáticas sobre a sua utilização, ou seja, entende-se o livro didático como um objeto cultural que, segundo Fonseca (2003, p. 56) "é uma das fontes de conhecimento histórico e, como toda e qualquer fonte, possui uma historicidade e chama a si inúmeros questionamentos".

Em relação ao livro didático como integrante da cultura material escolar, Bittencourt (2008a, p. 216) argumenta que

o livro didático deveria desempenhar o papel homogeneizador do saber escolar, de reforçar os métodos de ensino baseados na memorização, em uma escola concebida como transmissora dos conhecimentos das diferentes disciplinas. O livro didático deveria ser utilizado como instrumento de memorização, ocasionando a prática do "saber de cor". Páginas e páginas eram repetidas oralmente, diante do professor e dos companheiros, inculcando um conhecimento superficial de difícil avaliação quanto a sua efetiva apreensão.

Pode-se inferir que a trajetória da escrita e dos usos do livro didático, por muito tempo, teve como principal objetivo a memorização de conteúdos e a visão do professor como um mero coadjuvante do processo de aquisição e transmissão do saber. Assim, a herança de uma cultura escolar baseada numa visão considerada tradicional e ultrapassada ainda pode estar contida no imaginário de quem utiliza o livro didático, principalmente do professor, que, por muitas vezes, ainda infere uma visão de um instrumento manipulador. 
Ao referir-se ao livro didático como componente da cultura material escolar, Choppin (2004) destaca que os livros escolares assumem múltiplas funções e não podem ser compreendidos como o único objeto metodológico escolar, mas sim, como um dos instrumentos metodológicos que podem auxiliar no processo de aprendizagem e "que podem variar consideravelmente de acordo com o ambiente sócio cultural, a época, as disciplinas, os níveis de ensino, os métodos e as formas de utilização”. (CHOPPIN, 2004, p. 553). O autor ainda destaca as seguintes funções do livro didático:

1. Função referencial, também chamada de curricular ou programática, desde que existam programas de ensino: o livro didático é então apenas a fiel tradução do programa ou, quando exerce o livre jogo da concorrência, uma de suas possíveis interpretações. [...] 2. Função instrumental: o livro didático põe em prática métodos de aprendizagem, propõe exercícios ou atividades que, segundo o contexto, visam a facilitar a memorização dos conhecimentos, favorecer a aquisição de competências disciplinares ou transversais, a apropriação de habilidades, de métodos de análise ou de resolução de problemas, etc. 3. Função ideológica e cultural: [...] Instrumento privilegiado de construção de identidade, geralmente ele é reconhecido, assim como a moeda e a bandeira, como um símbolo de soberania nacional e, nesse sentido, assume um importante papel político. [...] 4. Função documental: acredita-se que o livro didático pode fornecer, sem que sua leitura seja dirigida, um conjunto de documentos, textuais ou icônicos, cuja observação ou confrontação podem vir a desenvolver o espírito crítico do aluno. (CHOPPIN, 2004, p. 553)

O livro didático é compreendido pela RSE como o instrumento do processo de ensino e aprendizagem mais importante. O seu efeito real não está apenas no conteúdo histórico apresentado, mas principalmente no modo de utilizá-lo e percebê-lo como ferramenta do professor. Assim, todos os elementos do processo de aprendizagem conjugam-se para dar um ou outro sentido ao livro didático. Como destaca Julia (2001, p. 34), "o manual escolar não é nada sem o uso que dele for realmente feito, tanto pelo aluno como pelo professor".

Entendendo a educação como seleção e organização do conhecimento científico em determinado tempo e espaço, percebe-se que a asserção ao currículo indica um caminho que necessita ser analisado. Assim, pensar em ensino de História é refletir sobre 
um novo currículo, numa nova maneira de sentir, pensar e fazer História. É repensar valores e crenças que foram reproduzidos durante décadas e séculos no contexto escolar.

Ao analisar os currículos escolares, deve-se ter presente que esses, no interior de seu texto, contêm um contexto social, econômico, cultural e político. Dessa forma, não pode ser entendido como um mero veículo de transmissão desinteressada do conhecimento social. Esse conhecimento, portanto, não pode apenas ser analisado como algo estático e naturalizado como um conjunto de conhecimentos para ser absorvido pelos professores e repassado aos alunos de maneira inquestionável.

Ao referir-se ao currículo, privilegia-se nesta pesquisa, que a construção e produção dele é um processo social o qual incorpora tendências e pensamentos de determinadas épocas e locais. Segundo Silva (1995, p. 7) “o currículo não é algo fixo, mas como um artefato social e histórico, está sujeito a mudanças e flutuações."

O currículo tal como o conhecemos atualmente não foi estabelecido, de uma vez por todas, em algum ponto privilegiado do passado. Ele está em constante fluxo e transformação, assim como, não se pode interpretar o currículo como resultado de um processo evolutivo, de contínuo aperfeiçoamento em direção a formas melhores e mais adequadas, mas sim, o currículo deve tentar captar as rupturas e disjunturas, surpreendendo na história, não apenas aqueles pontos de continuidade e evolução, mas também as grandes descontinuidades e rupturas. (SILVA, 1995, p. 7)

Nesse sentido, a formação de um currículo específico de História para os alunos do ensino médio da RSE, implica considerar que a instituição, como órgão de escolarização, possui seus objetivos pedagógicos, assim como interesses na constituição de identidades e na produção de uma cultura escolar. Como reforça Silva (1995, p. 8), “o currículo não é constituído de conhecimentos válidos, mas de conhecimentos considerados socialmente válidos." O autor ainda realça que as instituições educacionais processam conhecimento, mas também, e em conexão com esses conhecimentos, processam pessoas. Assim, “diferentes currículos produzem diferentes pessoas, mas naturalmente essas diferenças 
não são meras diferenças individuais, mas diferenças sociais, ligadas à classe, à raça, ao gênero." (SILVA, 1995, p. 10).

Assim, ao referir-se a formação de sujeitos no processo de escolarização, ressaltase a formação de identidades. Nesse aspecto, no que diz respeito ao currículo como formador e produtor de identidades, Silva (1999, p. 27) contribui argumentando que

não é preciso dizer que a educação institucionalizada e o currículo oficial ou não - estão, por sua vez, no centro do processo de formação de identidade. O currículo, como um espaço de significação, está estreitamente vinculado ao processo de formação de identidades sociais. É aqui, entre outros locais, em meio a processos de representação, de inclusão e de exclusão, de relações de poder, enfim, que, em parte, se definem, se constroem, as identidades sociais que dividem o mundo social. [...] Dessa perspectiva, o currículo não pode ser visto simplesmente como um espaço de transmissão de conhecimentos. O currículo está centralmente envolvido naquilo que somos, naquilo que nos tornamos, naquilo que nos tornaremos. O currículo produz, o currículo nos produz.

Levando em conta a produção de conhecimento, entende-se que o currículo não deve estar focado apenas no currículo em si, mas também no currículo como fator de produção de sujeitos. Silva (1995, p. 10) destaca que

o currículo deve ser visto não apenas como a expressão ou a representação ou o reflexo de interesses sociais determinados, mas também como produzindo identidades e subjetividades sociais determinadas. O currículo não apenas representa, ele faz. É preciso reconhecer que a inclusão ou exclusão no currículo tem conexões com a inclusão ou exclusão da sociedade.

Ao direcionar a análise do currículo para a produção de identidades, os autores dos livros didáticos de História do ensino médio da RSE definem qual o aluno que se pretende formar: 
Questionadores e competentes na sua capacidade de ler e participar do mundo em que vivem, para isso dotados com as habilidades que fortalecem a liberdade de espírito: curiosidades e aberturas ao exterior (do que é dito, ensinado, conhecido, recebido); capacidade de aprender por si mesmos; capacidade de problematizar; prática de estratégias cognitivas; possibilidade de verificar e eliminar o erro; invenção e criação; consciência reflexiva, ou seja, a capacidade de se autoconhecer, autopensar e autojulgar (consciência moral). (GRANGEIRO; MACHADO, 2006, p. 38)

Na mesma dimensão, ao se referir à formação de alunos da RSE, ainda de acordo com os autores dos livros didáticos, o objetivo do Projeto Pedagógico da Rede está voltado para "formar um cidadão comprometido com a dignidade humana e a vida; autônomo, crítico, solidário e capaz de respeitar as diferenças culturais." (GRANGEIRO; MACHADO, 2006, p. 36). Para atingir a proposta de formação dos alunos de acordo com esse padrão, o conjunto de autores da área de Ciências Humanas ${ }^{7}$ definiu a seleção de conteúdos em torno dos seguintes eixos: identidade, diversidade, cidadania, humanismo e transcendência ${ }^{8}$.

Pensar o currículo nessa concepção proposta pelos autores da Rede implica pensar num currículo que vai além da sala de aula. Convém pensar num currículo que considera a multiculturalidade dos grupos sociais no interior dos conteúdos selecionados para serem ensinados. Ao considerar a multiculturalidade, Sacristán (1995, p. 82) contribui para a análise afirmando que

discutir a integração de minorias sociais, étnicas e culturais ao processo de escolarização constitui uma manifestação muito concreta de um objetivo mais geral: o da educação multicultural. Por outro lado, a busca

\footnotetext{
7 De acordo com a definição do Projeto Pedagógico da RSE, as coleções de História, Geografia e Ensino Religioso integram a área de Ciências Humanas.

${ }^{8}$ De acordo com os autores do livro didático, assim são conceituados os eixos: (a) Identidade: um processo, ao mesmo tempo individual e social, em que a pessoa tende a definir seu lugar social e suas relações com os outros. (b) Diversidade: reconhecimento da diferenciação entre pessoas, classes, grupos humanos, no interior das sociedades e entre diferentes etnias e culturas. (c) Humanismo: reconhecimento do valor do ser humano na sua plenitude e a intenção de entendê-lo em seu mundo, que é o da natureza e da história. (d) Transcendência: a relação com o sagrado, com a fé e as diferentes respostas dadas aos "mistérios" de diferentes culturas, povos, sociedades. (e) Cidadania: como construção social que se enraíza numa cultura política, dependendo das lutas travadas socialmente e das concepções que se sustentam sobre elas. (GRANGEIRO; MACHADO, 2006, p. 37-38)
} 
de um currículo multicultural para o ensino é outra manifestação particular de um problema mais amplo: a capacidade da educação para acolher a diversidade. Partiremos da observação de que a cultura escolar não poderá, em seus conteúdos e práticas, levar em consideração e fazer com que os membros de uma minoria cultural se sintam acolhidos, se toda a cultura escolar não trata adequadamente o problema mais geral do currículo multicultural; e não se poderá chegar a esse se não se discute a questão da diversidade em geral.

Considerar a diversidade e multiculturalidade, assim como os demais eixos que direcionam a escolha dos conteúdos a serem ensinados para os alunos que frequentam as escolas salesianas é considerar o currículo escrito em consonância com o currículo real, ou seja, um currículo que procura articular teoria e prática. Sacristán (1995, p. 88) destaca que "um currículo multicultural no ensino implica mudar não apenas as intenções do que queremos transmitir, mas os processos internos que são desenvolvidos na educação institucionalizada".

A utilização do livro didático da Rede é parte fundamental para a concretização da proposta do aluno que se deseja formar, como formar e para que formar, pois, para torná-la possível, é necessária uma estrutura curricular diferente e uma mentalidade diferente, por parte de professores, pais, alunos, administradores e agentes que elaboram os livros didáticos, para a formação de uma cultura escolar, especificamente, salesiana.

Em relação ao material pedagógico, Sacristán (1995, p. 89) argumenta que

todos os materiais pedagógicos que são utilizados por professores e alunos são mediadores muito decisivos da cultura nas escolas, porque são os artífices do que e do como se apresenta essa cultura a professores e alunos. Ali se reflete de forma bastante elaborada a cultura real que se aprende. Esta é a razão pela qual os materiais são elementos estratégicos para introduzir qualquer visão alternativa da cultura.

Entre a elaboração do currículo como conjunto de declarações ou planos, em que se estabelecem os objetivos ou conteúdos que serão ensinados, o currículo que se 
desenvolve na prática aparece diretamente no livro didático. Especificamente o currículo de História do ensino médio da RSE está explícito diretamente no livro didático e faz parte da cultura material das escolas da Rede. Nesse sentido, deve-se considerar que a forma de selecionar e desenvolver os conteúdos do currículo faz parte de toda a configuração histórica das práticas educativas, das instituições e principalmente da execução dos conteúdos pelos professores. É fundamental para o Projeto Pedagógico da Rede tanto a elaboração do currículo explícito (escrito) por meio dos conteúdos do livro didático, quanto o currículo real por intermédio da prática do professor em sala de aula.

A cultura escolar delimitada pelo currículo explícito e por esse currículo real que se plasma nas práticas escolares ou por aquele que vemos refletido nos materiais pedagógicos - especialmente nos livros didáticos - está longe de ser um resumo representativo de todos os aspectos, dimensões ou invariantes da cultura da sociedade na qual surge o sistema escolar. O currículo seleciona elementos, valoriza mais certos componentes em relação a outros e também oculta dos alunos certos aspectos da cultura que rodeia a escola. (SACRISTÁN, 1995, p. 97)

Nessa linha de pensamento, pode-se inferir que o processo de produção do currículo é um processo social, no qual se consideram os fatores epistemológicos, culturais e sociais.

Dessa maneira, ao considerar que a educação representa uma condensação do social na qual os diferentes grupos refletem e projetam suas visões e expectativas, o currículo acaba por expressar a forma como são definidos os conteúdos a serem ensinados. Portanto,

o currículo escrito não passa de um testemunho visível, público e sujeito a mudanças, uma lógica que se escolhe para, mediante sua retórica, legitimar uma escolarização. Como tal, o currículo escrito promulga e justifica determinadas intenções básicas de escolarização, à medida que vão sendo operacionalizadas em estruturas e instituições. [...] Em síntese, o currículo escrito nos proporciona um testemunho, uma fonte documental, um mapa do terreno sujeito a modificações, constitui também um dos melhores roteiros oficiais para a estrutura institucionalizada da escolarização. (GOODSON, 1995, p. 21) 
Enfim, pensar num currículo que ultrapasse as barreiras do oficial, do escrito, do formal, implica pensar uma postura profissional do professor perante os desafios do mundo, assim como sua atualização constante. Segundo Sacristán (1995), do ponto de vista pedagógico, o importante não são as declarações ou os desejos sobre aquilo que se pretende introduzir nos currículos, mas a experiência que é vivida pelo aluno. Quando se entende a cultura não somente como os conteúdos, convém pensar que em toda experiência de aquisição se entrecruzam crenças, aptidões, valores, atitudes e comportamentos, porque são sujeitos reais que lhes dão significados, a partir de suas vivências como pessoas.

O currículo é produzido de acordo com os autores que o constroem, e estes estão vinculados aos lugares de produção e à política cultural e econômica de onde eles falam, assim como a corrente historiográfica da qual os autores compactuam.

Certeau (2010, p. 66) destaca que

toda pesquisa historiográfica se articula como um local de produção sócio- econômico, político e cultural. Implica um meio de elaboração que circunscrito por determinações próprias: uma profissão liberal, um posto de observação ou de ensino, uma categoria de letrados, etc. Ela está, pois, submetida a imposições, ligada a privilégios, enraizada em uma particularidade. É em função deste lugar que se instauram os métodos, que se delineia uma topografia de interesses, que os documentos e as questões, que lhe serão propostas, se organizam.

Nessa direção, pode-se considerar que o currículo é uma estratégia na construção da escola como formadora de sujeitos e espaço de relações sociais, nos quais se concentram e se desdobram as lutas em torno dos diferentes significados sobre o social, o político e o cultural.

É por meio do currículo entendido como elemento discursivo da política educacional, que os diferentes grupos sociais, especialmente os dominantes, expressam sua visão de mundo, seu projeto social, sua 'verdade'. Mesmo que não tivessem nenhum outro efeito, nenhum efeito no nível da escola e da sala de aula, as políticas curriculares, como texto, 
como discurso são, no mínimo, um importante elemento simbólico do projeto social dos grupos do poder. (SILVA, 1999, p. 10)

Portanto, a construção curricular refere-se à construção do currículo escrito/ formal, e, especificamente, no currículo de História do ensino médio da RSE, no qual as novas correntes historiográficas ganham espaço, o currículo de História é expresso por meio do livro didático.

No que concerne à análise da concepção historiográfica que direciona o currículo de História do ensino médio da RSE, no MP percebe-se uma intencionalidade dos autores em aproximar os conteúdos abordados no livro com a Nova História. ${ }^{9}$ No discurso dos autores, ao selecionar os temas da coleção, procura-se "dar visibilidade e voz aos grupos sociais no interior das sociedades ou a povos com cultura diferente da ocidental: povos muitas vezes silenciados e excluídos da memória Histórica." (ROTA; MACHADO, 2009, p. 39). Os autores ainda completam dizendo que entendem a História como uma prática social, em que o diálogo entre presente e passado permite "recuperar" ações e representações da ação dos diversos sujeitos que participam ou participaram da história. Procuram entender os desafios e conflitos em cada tempo e lugar de modo a perceber como os sujeitos enfrentaram os desafios e conflitos.

Ao se querer dar visibilidade aos povos com culturas diferenciadas, entende-se o currículo como uma construção e produção cultural, pois assim como a cultura, o currículo não é um produto pronto e acabado. Para um melhor entendimento sobre essa questão, Silva (1999, p. 19) defende que

\footnotetext{
${ }^{9}$ A Nova História é uma corrente historiográfica que, de acordo com Burke (1992), conquistou espaço na historiografia com os escritos de Le Goff da década de 1970 e 1980, principalmente os três volumes "novos problemas", "novas abordagens" e "novos objetos". Aos poucos, também conquista espaço entre os historiadores e consequentemente influencia na maneira de pensar e elaborar o conhecimento histórico a ser ensinado em sala de aula. Assim, a partir das décadas de 70 e 80, novos olhares foram direcionados para a escrita da História, buscando um direcionamento para as análises culturais dos acontecimentos históricos, assim como a utilização de novas fontes e outras vozes antes não ouvidas. Ou seja, na Nova História, o historiador faz parte do movimento da História trazendo uma multiplicidade de enfoques. É uma história problema que pretende uma nova maneira de pensar, sentir e fazer História, estendendo-se da produção acadêmica para o contexto escolar, principalmente nas discussões sobre os novos direcionamentos na elaboração do currículo escolar.
} 
a cultura é, sobretudo, atividade, ação, experiência. [...] dizer que os materiais existentes, as matérias vistas como produtos, como coisas, não estão aí apenas para ser contempladas ou para ser simplesmente recebidas, aceitas e passivamente consumidas. A cultura nunca é apenas consumo passivo. Os significados, os sentidos recebidos, a matéria significante, o material cultural são, sempre, embora às vezes de forma desajeitada, oblíqua, submetidos a um novo trabalho, a uma nova atividade de significação. São traduzidos, transpostos, deslocados, condensados, desdobrados, redefinidos, sofrem, enfim, um complexo e indeterminado processo de transformação.

Nessa perspectiva, pressupõe-se que trabalhar com a História vai muito além da formação intelectual ou cognitiva do aluno. Estabelece-se uma relação com a formação do cidadão ativo e capaz de compreender o mundo no qual está inserido e reconhecer-se como sujeito integrante de um grupo social e cultural capaz de entender o seu tempo.

A escolha dos conteúdos da coleção da Rede foi feita pelos autores, que, segundo a parte específica do professor ( ROTA; MACHADO, 2009, p. 36), estão de acordo com as diretrizes dos PCNs. A distribuição dos conteúdos não é organizada de forma linear, quer dizer, não seguem a clássica periodização baseada tão somente na cronologia e na História quadripartite. Os conteúdos são divididos por eixos norteadores distribuídos de acordo com as três séries do ensino médio. A escolha por eixos temáticos realizada pelos autores justifica-se pelo fato de "propiciar aos alunos condições de aproximação e análise da realidade social presente, coisa que muitas vezes é difícil de se conseguir quando a opção é pela sucessão linear da história de todos os povos, da Pré-História até os dias atuais" (ROTA; MACHADO, 2009, p. 32). De acordo com esse entendimento, assim está distribuído e organizado o currículo de História da RSE:

\begin{tabular}{|l|l|}
\hline Série & Conteúdos \\
\hline Volume $1-1^{\text {a }}$ série do & Unidade 1 - Identidades em construção \\
ensino médio & 1- Jovens, juventudes, histórias \\
2- Jovens em outras culturas \\
Unidade 2 - A invenção da cidadania \\
3- Cidade, cidadania, democracia: a experiência dos gregos \\
4- Os romanos e sua experiência republicana \\
5- Revolução Francesa, cidadania e democracia \\
Unidade 3 - A construção do mundo moderno \\
6- Tempo, espaço e modernidade \\
\hline
\end{tabular}




\begin{tabular}{|c|c|}
\hline & $\begin{array}{l}\text { 7- Ordem e desordem na modernidade: o tempo da } \\
\text { política e o Estado moderno } \\
\text { 8- Na busca pelo paraíso, a descoberta do outro }\end{array}$ \\
\hline $\begin{array}{l}\text { Volume } 2-2^{a} \text { série do } \\
\text { ensino médio }\end{array}$ & $\begin{array}{l}\text { Unidade } 1 \text { - A produção do mundo contemporâneo } \\
\text { 1- Artesãos e camponeses na Europa medieval } \\
\text { 2- No ritmo da indústria } \\
\text { 3- Trabalhadores de todo o mundo, uni-vos! } \\
\text { Unidade } 2 \text { - Terra e poder } \\
\text { 4- Terra e poder na América Latina } \\
\text { 5- O acesso à terra no Brasil, ordem e (des)ordem } \\
\text { 6- O concerto das nações ou o massacre dos povos } \\
\text { Unidade } 3 \text { - Mundos do trabalho no Brasil } \\
\text { 7- Entre o cativeiro e a liberdade } \\
\text { 8- Trabalho, indústria e movimento operário } \\
\text { 9- Riquezas e misérias: duas faces da construção do Brasil }\end{array}$ \\
\hline $\begin{array}{l}\text { Volume } 3-3^{\mathrm{a}} \text { série do } \\
\text { ensino médio }\end{array}$ & $\begin{array}{l}\text { Unidade } 1 \text { - Estados, nações e nacionalismos } \\
\text { 1- A formação das nações ou o mundo à beira da guerra } \\
\text { 2- A (difícil) construção da nação brasileira } \\
\text { 3- Estados Unidos: formando uma nação } \\
\text { Unidade } 2 \text { - Os dilemas do século XX } \\
\text { 4- Brasil: a ordem republicana ou como eliminar a } \\
\text { participação popular } \\
\text { 5- O capitalismo contestado ou a construção do mundo } \\
\text { comunista } \\
\text { 6- Guerras e crises capitalistas } \\
\text { Unidade } 3 \text { - Autodeterminação dos povos e novas formas de } \\
\text { dominação } \\
\text { 7- Os países “pobres" no cenário mundial } \\
\text { 8- Nova ordem mundial? } \\
\text { 9- Brasil, um país de desigualdades e diversidades }\end{array}$ \\
\hline
\end{tabular}

Quadro 3: Organização dos conteúdos da coleção de História do ensino Médio da RSE

Fonte: Volume 1: ROTA, MACHADO, 2009. Volume 2: GRANGEIRO; MACHADO, 2005. Volume 3: GRANGEIRO; MACHADO, 2006.

Os autores ainda salientam que a decisão de buscar outras formas de organização curricular, não vinculadas a modelos tradicionais de linearidade cronológica, foi apoiado nos PCNs: “Trabalhar o tempo como duração ajudará os alunos a perceberem diferentes temporalidades, a partir da identificação das mudanças e permanências no modo de vida dos grupos sociais" (ROTA; MACHADO, 2009, p. 40). 
Porém, Rota e Machado (2009, p. 40) destacam a importância do não abandono total da cronologia, pois "falar em tempo é também falar de periodização: quem periodiza assume a escolha do que deve ser lembrado como marco histórico, definidor de tempos diferentes, e consolida certo modo de olhar para esses marcos: impõe portanto uma memória".

Ao referir-se a análise de um livro didático e ao seu conteúdo histórico escolar, Bittencourt (2008b, p. 313) destaca que

\begin{abstract}
a análise da bibliografia, assim como da seleção de documentos ou excertos de determinadas obras historiográficas, contribui para a percepção da tendência histórica predominante. A bibliografia indica também o nível de atualização do autor do livro, ao passo que a indicação de leituras complementares para professores e alunos é outro elemento importante para verificação.
\end{abstract}

A autora ainda chama a atenção para que o professor esteja atento à organização dos conteúdos escolares, à corrente historiográfica que os autores se baseiam e à maneira como a escrita da História é veiculada no livro didático.

Tendo em consideração a distribuição dos conteúdos e a fala dos autores do livro didático de História da RSE, a temporalidade histórica é compreendida como um processo histórico, o tempo como processo vivo, instável e em constante reconstrução sob diferentes olhares, apreendendo noções como duração/rupturas e mudanças/permanências. Assim, compreender a História, levando em conta as suas múltiplas temporalidades, é compreendê-la na relação entre passado, presente e futuro.

Nessa perspectiva, a organização curricular dos conteúdos históricos do livro didático pode ajudar a compreender esse processo de construção histórica como um movimento entre o passado e o presente, assim como noções de duração, permanências, mudanças e rupturas. Em outras palavras, a influência do livro didático deve ser entendida e compreendida como um mecanismo na produção do pensamento histórico e como produto de uma cultura escolar específica. 


\section{Considerações}

Na RSE o livro didático é considerado parte integrante dos dispositivos curriculares e é tomado pela Instituição como o principal recurso metodológico dos docentes. No entanto, é nos processos de mediação didática, ainda a ser inquiridos com maior acuidade, que se observa a importância atribuída a esse componente da cultura escolar.

De acordo com a equipe pedagógica da RSE e dos autores dos livros didáticos, as aulas de História deveriam ser encaminhadas seguindo as normativas incluídas no MP de cada livro e estes deveriam ser utilizados como principal ferramenta pelo professor nas suas aulas. Porém, o que se observou nas escolas pesquisadas, nos alunos e professores ouvidos na pesquisa, é que os usos e as apropriações do livro didático são adaptados por condições que se relacionam de modo complexo, quer dizer, cada escola (mais especificamente cada professor) se adapta e utiliza o livro didático de acordo com as representações que dele faz, sejam representações vinculadas ao livro como suporte e direcionamento das suas aulas, sejam representações de resistência ao livro limitando a sua utilização em sala de aula. Ou seja, há que se destacar que o livro didático é componente de uma cultura escolar e o mesmo por si só não dá conta de tratar da historicidade dos conceitos, da problemática em torno das diferentes formas de apreensão do conhecimento, mas no conjunto da prática pedagógica forma-se e transforma-se num dos principais artefatos materiais da cultura escolar.

Enfim, como argumenta Forquin (1993, p. 17), a cultura escolar é "dotada de uma dinâmica própria [...], sustentando com as outras dinâmicas culturais [...] relações complexas e sempre sobre determinadas, de nenhum modo redutíveis, em todo caso, aos processos de simples reflexo [...]". Ou seja, é perceptível nas escolas salesianas do estado catarinense a formação de uma nova cultura escolar no contexto da Rede; considera-se, no entanto, as especificidades culturais e os diferentes mecanismos de administração escolar nas cinco escolas pesquisadas. 


\section{Referências}

BISEWSKI, Osvaldo. Práticas de formação continuada de professores: estudo de caso na rede Salesiana de Escolas. 2008. 100 f. Dissertação (Mestrado em Educação nas Ciências) - Universidade do Noroeste do Estado do Rio Grande do Sul, Rio Grande do Sul, 2008

BITTENCOURT, Circe Maria Fernandes. Livro didático e saber escolar (1810-1910). Belo Horizonte: Autêntica Editora, 2008a.

BITTENCOURT, Circe Maria Fernandes. Ensino de história: fundamentos e métodos. 2. ed. São Paulo: Cortez, 2008b.

BITTENCOURT, Circe. O saber histórico na sala de aula. 11. ed. São Paulo: Contexto, 2006.

BOURDIEU, Pierre; PASSERON, Jean-Claude. A reprodução: elementos para uma teoria do sistema de ensino. Trad. de Reynaldo Bairão. Rio de Janeiro: Francisco Alves, 1982.

BURKE, Peter. A escrita da história: novas perspectivas (Org.); tradução de Magda Lopes. São Paulo: Editora da UNESP, 1992.

CERTEAU, Michel de. A escrita da história. Tradução de Maria de Lourdes Menezes; revisão técnica de Arno Vogel.- 2 ed.- Rio de Janeiro: Forense Universitária, 2010.

CHOPPIN, Alain. História dos livros e das edições didáticas: sobre o estado da arte. Educação \& Pesquisa. São Paulo, v. 30, n. 3, p. 549-566, set./dez. 2004.

FONSECA, Selva Guimarães. Didática e prática de ensino de história: Experiências, reflexões e aprendizados. Campinas, SP: Papirus, 2003.

FORQUIN, Jean-Claude. Escola e cultura: as bases sociais e epistemológicas do conhecimento escolar. Porto Alegre: Artes Médicas, 1993.

GATTI JUNIOR, Décio \& OLIVEIRA, Lúcia Helena Moreira de Medeiros. História das instituições educativas: um novo olhar historiográfico. Cadernos de História da Educação. Uberlândia.v.1., n. 1, p.73-76, jan./dez. 2002.

GOODSON, Ivor F. Currículo: teoria e história. Tradução de Atílio Brunetta; Revisão da tradução: Hamilton Francischetti; apresentação de Tomaz Tadeu da Silva. Petrópolis, RJ: Vozes, 1995.

GRANGEIRO, Cândido Domingues; MACHADO, Ronilde Rocha. História: ensino médio, $2^{\circ}$ ano. Brasília: Cisbrasil - CIB, 2006.

JULIA, Dominique. A cultura escolar como objeto histórico. Revista Brasileira de História da Educação, Campinas, n. 1, p. 9-44, 2001.

OLIVEIRA, Margarida Maria Dias de. Livros didáticos de história: pesquisa, ensino e novas utilizações deste objeto cultural. In: OLIVEIRA, Margarida Maria Dias de; OLIVEIRA, Almir Félix Batista de Oliveira. Livros didáticos de História: escolhas e utilizações. Natal, RN: EDFURN, 2009. 
SACRISTÁN, Gimeno J. Currículo e diversidade cultural. In: SILVA, Tomaz Tadeu da. MOREIRA, Flávio Antonio. (Org.) Territórios contestados: o currículo e os novos mapas políticos e culturais. Petrópolis, RJ: Vozes, 1995.

SILVA, Tomaz Tadeu da. MOREIRA, Flávio Antonio. (Org.) Territórios contestados: o currículo e os novos mapas políticos e culturais. Petrópolis, RJ: Vozes, 1995.

SILVA, Tomaz Tadeu da. O currículo como fetiche: a poética e a política do texto curricular. Belo Horizonte: Autêntica, 1999.

REDE SALESIANA DE ESCOLAS. - Projeto pedagógico: marco referencial. São Paulo: SER, Salesiana, 2005.

ROTA, Paulo Storace; MACHADO, Ronilde Rocha. História: ensino médio, $1^{\circ}$ ano. $2^{\mathrm{a}}$ ediç̧ão. Brasília: Cisbrasil - CIB, 2009.VIDAL, Diana Gonçalves: SCHWARTZ, Cleonara Maria. Sobre cultura escolar e historia da educação : questões para debate. In: VIDAL, Diana Gonçalves: SCHWARTZ, Cleonara Maria (Orgs.). História das culturas escolares no Brasil. Vitória: EDUFES/SBHE, v.1, 2010. (Coleção Horizontes da Pesquisa em História da Educação no Brasil).

VIÑAO-FRAGO, Antonio; ESCOLANO, Agustín Benito. Currículo, espaço e subjetividade: a arquitetura como programa. Tradução de Alfredo Veiga-Neto. Rio de Janeiro: DP\&A. 1998.

Universidade do Estado de Santa Catarina - UDESC Programa de Pós-Graduação em Educação - PPGE 